\title{
Effects of COVID-19 Outbreak on Children's Mental Health: A Comparative Study with Children Diagnosed and Isolated from Their Parents
}

\author{
Şenay Kılınçel', Feray Tarımtay Altun², Özgecan Nuryüz ${ }^{3}$, Ezgi Tan ${ }^{4}$, Erkal Erzincan", \\ Oğuzhan Kılınçel ${ }^{6}$, Esra Yazıcı ${ }^{7}$, and Muhammed $\mathrm{Ayaz}^{3 凶}$ \\ ${ }^{1}$ Sakarya Child and Adolescent Psychiatry Institute, Sakarya, Turkey \\ 'University of Health Sciences, Department of Clinical Psychology, Istanbul, Turkey \\ ${ }^{3}$ Mentalica Consultancy Education and Research Center, Istanbul, Turkey \\ ${ }^{4}$ Department of Psychology, Istanbul Ticaret University, Istanbul, Turkey \\ ${ }^{5}$ Department of Psychology, Istanbul Gelisim University, Istanbul, Turkey \\ ${ }^{6}$ Department of Psychiatry, Sakarya Yenikent State Hospital, Sakarya, Turkey \\ ${ }^{7}$ Department of Psychiatry, Sakarya University Medical Faculty, Sakarya, Turkey
}

Objective The COVID-19 outbreak has negatively affected children in many ways. This study aimed to compare the psychological responses of children exposed to different levels of stress during the COVID-19 outbreak.

Methods The anxiety levels, negative thoughts, and quality of life of COVID-19-positive children with COVID-19-positive parents (Child+ group, $\mathrm{n}=17$ ), COVID-19-negative children who are separated from COVID-19-positive parents (Parent+ group, $\mathrm{n}=59$ ), and a control group ( $\mathrm{n}=64$ ) were compared. The participants completed the Screen for Child Anxiety and Related Disorders (SCARED), Children's Negative Cognitive Errors Questionnaire (CNCEQ), and Pediatric Quality of Life Inventory (PedsQL).

Results The statistical analysis revealed that the Parent+ group recorded higher SCARED and CNCEQ scores and lower PedsQL scores in comparison with the control group. No statistically significant difference was found between the scores of the Child+ and control groups. Furthermore, high CNCEQ scores and low PedsQL scores in the Parent+ group predicted an increase in their SCARED scores.

Conclusion Our study indicates that separating children from their parents during the COVID-19 outbreak negatively influences their mental health and increases their anxiety levels.

Psychiatry Investig 2021;18(2):140-146

Key Words COVID-19, Child, Anxiety, Negative cognition, Quality of life.

\section{INTRODUCTION}

COVID-19 was first observed in December 2019. The virus has since rapidly spread across the world and has become a pandemic. ${ }^{1}$ The ongoing COVID-19 crisis has negatively influenced the physical and mental health of children and adolescents as well as adults. ${ }^{2}$ The psychological responses of children to stressful events differ from the reactions of adults because

Received: October 8, 2020 Revised: November 12, 2020

Accepted: November 27, 2020

$\triangle$ Correspondence: Muhammed Ayaz, MD

Mentalica Consultancy Education and Research Center, Altayçeşme Mah. Öz Sokak, 19/5, 34843, Maltepe, İstanbul, Turkey

Tel: +90 53330238 93, E-mail: ayazmuhammed@yahoo.com

(c) This is an Open Access article distributed under the terms of the Creative Commons Attribution Non-Commercial License (https://creativecommons.org/licenses/bync/4.0) which permits unrestricted non-commercial use, distribution, and reproduction in any medium, provided the original work is properly cited. the former cannot appropriately express their emotions and have not yet developed adequate coping skills. ${ }^{3}$ The most common symptoms reported for children and adolescents during the pandemic include behavioral problems, fears related to the infection of their loved ones, distractibility, and irritability. ${ }^{4}$

Children may experience symptoms such as anxiety, depression, and loss of appetite when confronted with negative events that influence their environments. ${ }^{5}$ The daily activities and habits of children and adolescents have been greatly transformed due to the home quarantines and school closures imposed during the outbreak. ${ }^{4}$ Quarantine restricts social and physical interactions and impairs daily routines. Thus, children cannot play and participate in activities as expected at their developmental level. ${ }^{5}$ In addition, factors such as the length of the quarantine period, fear of infection, distancing from friends and teachers, and financial losses in families could lead to mental 
health symptoms in children and adolescents, who may experience depression or anxiety. ${ }^{6}$ A study conducted in China to observe how outbreaks affect the mental health of children reported that $18.9 \%$ of the participants evidenced an increase in anxiety symptoms. ${ }^{6}$ One study suggested that the anxiety symptoms demonstrated by children and adolescents diagnosed with COVID-19 differ in accordance with the age and developmental level.?

Children and adolescents also exhibit varying psychological reactions to social and emotional difficulties. ${ }^{8}$ The ways by which children interpret the events they must confront also influence their psychological responses. ${ }^{9}$ Some children generate negative ideas about events because of cognitive errors, such as personalization, generalization, and catastrophizing. These negative thoughts or interpretations cause them to ignore the positive aspects of their circumstances and overemphasize negativities. ${ }^{10}$ Negative thoughts mediate the emotional and behavioral problems that may develop after critical life events. ${ }^{11-13}$ Several studies show that negative thoughts in children are particularly associated with depression and anxiety. ${ }^{14}$

Measures implemented to prevent the spread of a disease during an outbreak may also result in numerous lifestyle changes. Parental mental health may be influenced by economic problems and unemployment caused by the need for social isolation; in turn, these elements can impair the quality of life of children. ${ }^{15}$ In addition, children feel an excessive sense of responsibility, and stressful life events at home may cause children to blame and punish themselves. ${ }^{16}$ Such circumstances can also negatively influence the quality of life of children and adolescents.

Changes in family life are among the stressors experienced during the ongoing COVID-19 outbreak that can affect the mental health of children. ${ }^{17}$ The most significant transformation is felt by the individual diagnosed with COVID-19 within a family. Being diagnosed, treated in hospitals, and isolated after treatment necessarily separate parents from children. When faced with stressors, children tend to observe the emotions and behaviors of their parents to regulate their emotions and shape their behaviors accordingly. ${ }^{18}$ Therefore, children need the guidance of their parents to be able to normalize their emotions and adjust their behaviors during outbreaks. Hence, children who lose contact with their parents due to quarantine measures may be at an increased risk of developing psychiatric disorders. ${ }^{18}$

Clinicians can better determine treatment strategies if they could comprehensively understand the mental health impacts of diseases or negative life events comprehend the risk factors. Limited research has been conducted on the etiology of mental health problems that may be triggered in children and the factors that could negatively impact the mental health of children during disease outbreaks..$^{18}$ In addition, only a few studies have examined the negative thoughts children may experience in times of health-related crises. The mental health problems of children caused by COVID-19 have not been examined in detail. Although an increase in their general anxiety levels has been reported, the relationship between children's anxiety levels and quality of life has not been studied to the best of the authors' knowledge. Negative life events, such as the ongoing outbreak, can influence the mental health of entire communities; however, the risk of developing a mental health problem is exacerbated by personally falling ill or having someone in the family contract the disease. The present study thus intends to evaluate the mental characteristics of children exposed to varying levels of stress during the ongoing COVID-19 outbreak.

Determining the factors that influence the experience of quarantined children and parents is essential in order to maximize disease containment and minimize the negative effects on those who are quarantined as well as families. To accomplish this purpose, this study compared COVID-19-positive children with COVID-19-positive parents, COVID-19-negative children separated from COVID-19-positive parents, and a control group in terms of anxiety levels, negative thoughts, and quality of life.

\section{METHODS}

\section{Participants}

The sample consisted of 140 children who were aged between 8 and 14 years and residing in Sakarya Province. There were three groups of children: children diagnosed with COVID-19 (Child+ group, n=17) from March 15 to May 15, 2020, with COVID-19-positive parents; COVID-19-negative children who were separated from COVID-19-positive parents (either or both parents) (Parent+ group, $\mathrm{n}=59$ ); and a randomly selected control group from the community sample $(n=64)$. Only laboratory-confirmed cases (SARS-CoV-2 RNA detected by the molecular method) were included in this study. The exclusion criteria were the presence of a neurological disease affecting cognitive functions, having mental disability, and autism spectrum disorders. Figure 1 outlines the sample selection process for all three groups.

\section{Measures}

\section{Sociodemographic data form}

The form was prepared by the researchers to examine sociodemographic variables that may be related to the influences of the COVID-19 outbreak on mental health. The form included questions such as age, gender, and educational status. 


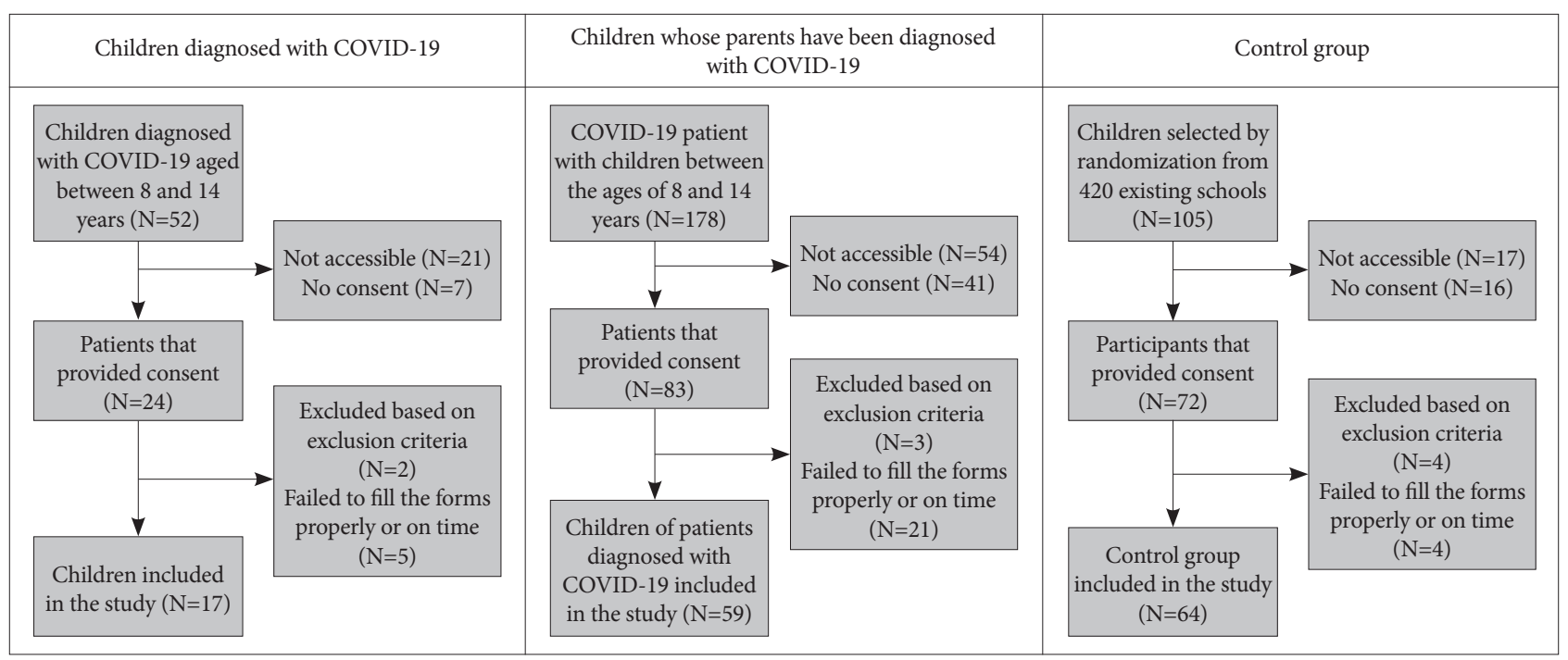

Figure 1. Sample selection of groups.

\section{Screen for Child Anxiety and Related Disorders (SCARED)}

Developed by Birmaher et al., ${ }^{19}$ SCARED is a self-report scale containing 41 items that measure anxiety in children. The children were asked to read the items, or someone else read the items to them and marked the most suitable option. This scale includes five factors: somatic/panic, generalized anxiety, social phobia or social anxiety, separation anxiety, and school phobia. Çakmakçı established the reliability and validity of the Turkish version of SCARED. ${ }^{20}$

\section{Children's Negative Cognitive Errors Questionnaire (CNCEQ)}

Developed by Leitenberg et al., ${ }^{21}$ CNCEQ was derived from cognitive theory and measures for types of cognitive errors: catastrophizing, overgeneralization, personalizing, and selective abstraction. CNCEQ is a Likert-type scale wherein high scores indicate high levels of cognitive errors. Karakaya et al..$^{22}$ established the reliability and validity of the Turkish version of CNCEQ.

\section{Pediatric Quality of Life Inventory (PedsQL)}

PedsQL was developed by Varni et al., ${ }^{23}$ and it evaluates the general quality of life of children and adolescents (aged between 2 and 18 years). This questionnaire includes four different forms for various age groups; this study used the 8-12 age form for the 8-12 age group and the 13-18 age form for the 13-14 age group. PedsQL includes four subscales: physical functioning (8 items), emotional functioning (5 items), social functioning (5 items), and school functioning (5 items). Çakın established the reliability and validity of the Turkish version of PedsQL. ${ }^{24,25}$

\section{Procedures}

The date of birth, diagnosis dates, and contact information of all COVID-19 patients were obtained from the Sakarya Provincial Health Directorate after the necessary permission was obtained for this study. Clinical psychologists contacted the parents of subjects whose age range matched the research criteria via phone and informed them about this study. Parental consent for participation was secured using an online form. The parents were required to fill out their children's sociodemographic questionnaire, and the children were asked to accomplish the other instruments. Video calls were used to support subjects who experienced difficulties in filling out their forms. Data compiled from the responses of 140 children were used for the statistical analyses performed for this study.

\section{Data analyses}

The software Statistical Program for Social Sciences 16 (SPSS 16, SPSS Inc., Chicago, IL, USA) was used for data analysis. The conformity of numerical variables (numerical data) to normal distribution was investigated by a visual method (histogram analysis) and analytical methods (Kolmogorov-Smirnov, and Shapiro-Wilk tests). The Mann-Whitney U test was performed for the statistical evaluation of numerical data that did not conform to normal distribution between two sample groups, and the Kruskal-Wallis test was performed for the evaluations performed between more than two groups. The Bonferronicorrected Mann-Whitney U test was used in the event of significant differences $(\mathrm{p}<0.05)$ found via the Kruskal-Wallis Test. Pearson correlation analysis was conducted to examine the associations between normally distributed numerical variables. Research data were evaluated considering a significance level of $\mathrm{p}<0.05$. Linear regression analysis was employed to examine the predictability of the sociodemographic variables and 
the SCARED questionnaire scores of the Parent+ group participants that reported high anxiety levels. The independent variables in the model were those that were normally distributed and had within-group p values less than 0.25 in the statistical analyses.

Permission to conduct the study was obtained from the Ethics Committee of the Faculty of Medicine of Sakarya (71522473/ 050.01.04/163) and the COVID-19 Scientific Research Board of the Ministry of Health of the Republic of Turkey (2020-0501T18_42_03).

\section{RESULTS}

Table 1 presents the outcomes of the comparative analysis of the sociodemographic characteristics of the groups and the scales used in this study. The three groups were similar in terms of age range and gender ( $p>0.05)$. No significant differences were found between the groups in terms of place of residence and the frequency of exposure to stressful situations within the family except the COVID-19 outbreak ( $p>0.05$ ). By contrast, statistically significant differences were observed between the groups in the SCARED ( $\mathrm{p}=0.013)$, CNCEQ $(\mathrm{p}=0.019)$, and PedsQL ( $\mathrm{p}=0.024)$ scores. Post-hoc analyses were conducted to observe the differences between the groups. The PedsQL scores were lower, and the SCARED and CNCEQ scores were higher in the Parent+ group than in the control group.

The SCARED scores were compared in terms of the sociodemographic variables in the Parent+ group, and the findings are presented in Table 2. No statistically significant differences in the SCARED scores were noted between the groups with re- gard to gender, residence, parental history of hospitalization, and exposure to a stressful situation in the family apart from the COVID-19 outbreak ( $\mathrm{p}>0.05$ ).

The correlation between the scale scores and the age variables in the Parent+ group was examined. A significant, strong positive correlation was observed between the SCARED and CNCEQ scores ( $r=0.938)$, and a significant moderate negative correlation was observed between the SCARED and PedsQL scores $(r=-0.610)$. There was a negative relationship between the SCARED scores and age $(r=-0.243)$, but no significant difference was noted between them. In addition, no statistically significant difference was noted between the SCARED scores and the time that had elapsed after the diagnosis of the parent $(r=0.071)$. Table 3 summarizes the results obtained from the correlation analysis between the SCARED scores and the other variables in the Parent+ group.

The results of the linear regression analysis that were used to

Table 2. Correlation between scales, age and COVID-19 releated variables in Parent+ group

\begin{tabular}{lcccc}
\hline & 1 & 2 & 3 & 4 \\
\hline 1-Age & - & & & \\
2-SCARED & -0.243 & - & & \\
3-PedsQL & 0.072 & $-0.610^{*}$ & - & \\
4-CNCEQ & -0.182 & $0.938^{*}$ & $-0.529^{*}$ & - \\
5-Days after the & -0.064 & -0.026 & -0.051 & -0.057 \\
parent's diagnosis & & & & \\
\hline
\end{tabular}

${ }^{*} \mathrm{p}<0.01$. SCARED: Screen for Child Anxiety and Related Disorders, PedsQL: Pediatric Quality of Life Inventory, CNCEQ: Children's Negative Cognitive Errors Questionnarie

Table 1. Comparison of sociodemoghraphic factors and scores of the scales used in the study between study groups

\begin{tabular}{|c|c|c|c|c|c|}
\hline & $\begin{array}{c}\mathrm{I} \\
\text { Child+ group }(\mathrm{N}=17)\end{array}$ & $\begin{array}{c}\text { II } \\
\text { Parent+ group }(\mathrm{N}=59)\end{array}$ & $\begin{array}{c}\text { III } \\
\text { Healthy control }(\mathrm{N}=64)\end{array}$ & $\mathrm{p}$ & $\begin{array}{c}\text { Post hoc analysis } \\
\text { results }\end{array}$ \\
\hline \multicolumn{6}{|l|}{ Age in years } \\
\hline Mean \pm SD (median) & $11.35 \pm 2.09(10.90)$ & $10.87 \pm 1.88(10.67)$ & $10.96 \pm 2.00(10.60)$ & $0.639^{\dagger}$ & \\
\hline Gender $(\mathrm{N}, \%)$ & & & & $0.198^{*}$ & \\
\hline Girl & $8(47.1)$ & $36(61.0)$ & $29(45.3)$ & & \\
\hline Boy & $9(52.9)$ & $23(39.0)$ & $35(54.7)$ & & \\
\hline Place of residence $(\mathrm{N}, \%)$ & & & & $0.199 *$ & \\
\hline Village /town & $10(58.8)$ & $38(64.4)$ & $31(48,4)$ & & \\
\hline City & $7(41.2)$ & $21(35.6)$ & $33(51.6)$ & & \\
\hline \multicolumn{6}{|l|}{ PedsQL } \\
\hline Mean \pm SD (median) & $81.59 \pm 16.19(82.00)$ & $77.88 \pm 11.85(79.00)$ & $83.80 \pm 9.43(85.50)$ & $0.019^{\dagger}$ & III $>$ II \\
\hline \multicolumn{6}{|l|}{ SCARED } \\
\hline Mean \pm SD (median) & $19.12 \pm 17.59(14.00)$ & $24.12 \pm 9.97(23.00)$ & $19.33 \pm 10.22(19.00)$ & $0.013^{\dagger}$ & 117111 \\
\hline \multicolumn{6}{|l|}{ CNCEQ } \\
\hline Mean \pm SD (median) & $34.53 \pm 10.52(30.00)$ & $36.92 \pm 6.36(36.00)$ & $34.33 \pm 6.26(34.00)$ & $0.024^{\dagger}$ & $11>111$ \\
\hline
\end{tabular}


Table 3. Comparison of children's SCARED scores based on sociodemographic variables and COVID-19 related variables in Parent+ group

\begin{tabular}{lcc}
\hline & $\begin{array}{c}\text { SCARED } \\
\text { Mean } \pm \text { SD (median) }\end{array}$ & $\mathrm{p}$ \\
\hline Gender (N, \%) & $0.205^{*}$ \\
Boy & $25.50 \pm 9.56(23.50)$ & \\
Girl & $21.96 \pm 10.42(20.00)$ & \\
Place of residence (N, \%) & & $0.739^{*}$ \\
$\quad$ Village/town & $23.97 \pm 10.89(22.00)$ & \\
City & $24.38 \pm 8.29(24.00)$ & \\
Parent's history of in-patient treatment for COVID-19 & $0.854^{*}$ \\
(N, \%) & \\
No & $24.47 \pm 9.43(24.00)$ & \\
Yes & $23.98 \pm 10.28(23.00)$ &
\end{tabular}

Presence of a stressful situation in family except disease $\quad 0.782 *$ during COVID-19 outbreak (N, \%)

$$
\begin{array}{lr}
\text { No } & 23.55 \pm 9.51(23.50) \\
\text { Yes } & 25.14 \pm 10.92(23.00)
\end{array}
$$

*Mann Whitney U test. SCARED: Screen for Child Anxiety and Related Disorders

Table 4. Results of the linear regression analysis with SCARED scores as outcome variable in Parent+ group

\begin{tabular}{lccccc}
\hline & $\mathrm{B}$ & $\begin{array}{c}\text { Standard } \\
\text { error }\end{array}$ & Beta & $\mathrm{t}$ & $\mathrm{p}$ \\
\hline Constant & -9.280 & 6.163 & & -1.506 & 0.138 \\
CNCEQ & 1.314 & 0.079 & 0.838 & 16.691 & 0.000 \\
PedsQL & -0.136 & 0.042 & -0.162 & -3.264 & 0.002 \\
Age & -0.415 & 0.226 & -0.078 & -1.836 & 0.072 \\
\hline
\end{tabular}

Adjusted $\mathrm{R}^{2}=0.898$. SCARED: Screen for Child Anxiety and Related Disorders, CNCEQ: Children's Negative Cognitive Errors Questionnaire, PedsQL: Pediatric Quality of Life Inventory

examine the factors predicting the SCARED scores in the Parent+ group are shown in Table 4. The regression model found that the CNCEQ and PedsQL scores predicted the SCARED scores, and the corrected $\mathrm{R}^{2}$ value was 0.889 .

\section{DISCUSSION}

This study compared the anxiety levels, negative thoughts, and quality of life of COVID-19-positive children with COVID-19-positive parents, COVID-19-negative children separated from COVID-19-positive parents, and a control group. The study also scrutinized factors predicting high anxiety levels in the group of COVID-19-negative children separated from parents who tested positive for COVID-19.

The literature review yielded limited information about the ways by which negative thoughts and anxiety affect children and parents diagnosed and quarantined during epidemics. An extant study that evaluated the psychological influences of quarantines during epidemics on different age groups indicated that negative emotions and ideas increase during quarantines. In addition, the study posited that the psychological effects caused by the quarantine experience are higher in younger age groups. ${ }^{26}$ Another study reported that $30 \%$ of the children who were isolated and quarantined during the H1N1 outbreak of 2009 exhibited considerable post-traumatic stress symptoms. The same study also found that generalized anxiety and adjustment disorders were common psychiatric difficulties experienced by individuals who received mental health services after that outbreak. ${ }^{27}$ The current study found that children separated from their parents demonstrated higher anxiety levels compared with the control group. No difference in anxiety levels was found between the Child+ group (COVID-19-positive children with COVID-19-positive parents) and the control group, given that all COVID-19-positive children in this study had at least one COVID-19-positive parent and thus were not separated. The potential impact of isolation is highlighted by this result. Most children diagnosed with COVID-19 are asymptomatic. ${ }^{28}$ Therefore, the higher anxiety levels and increased negative thoughts evidenced in the present study during the current outbreak could result from children's fear of their parents leaving or dying rather than the children's fear of being afflicted themselves.

The children whose parents were diagnosed as COVID19-positive and were separated from them during the quarantine period exhibited more negative thoughts. These children experienced a heightening of negative feelings, such as hopelessness and weakness that led to a sense of insecurity, when their parents were infected by a sudden and unknown lifethreatening disease. ${ }^{29,30}$ Being with parents during a health crisis gives children confidence and reduces their anxiety. ${ }^{31} \mathrm{By}$ contrast, the strict visiting restrictions and inability to see parents during illnesses such as COVID-19 causes children to feel excluded and lonely. ${ }^{32}$ Children who do not receive adequate and correct information about the medical condition of their parents seem to bridge the gaps left by the missing information with negative thoughts and ruminatively focus on these unconstructive ideas. ${ }^{33}$ We had limited knowledge about the conditions under which the children remained in quarantine when they were isolated from their parents and about the factors that caused the increase in their negative thoughts during isolation. Nonetheless, the diagnosis of COVID-19 among the parents and the children's separation from their parents may have been important factors that led to an increase in negative thoughts among the children.

This study also revealed that the children whose parents were diagnosed with COVID-19 had poor quality of life compared with the control group. When a parent contracts an acute illness, sudden changes occur in the family's daily life, and a child 
may have difficulties adapting to these changes in a short time. ${ }^{34}$ Adjustment problems increase, particularly in cases of hospitalization and the need for intensive care confinement because of the illness. ${ }^{35}$ The literature review did not yield any study on the influences exerted by quarantines on the quality of life of children whose parents have infectious illnesses. Our results suggest that separation from parents during the COVID-19 outbreak played a crucial role in the decrease observed in the children's quality of life.

A decrease in the quality of life and an increase in negative thoughts leading to elevated anxiety levels were noted in the children whose parents were diagnosed with COVID-19. A negative correlation was previously evidenced between anxiety levels and the quality of life of children whose parents are diagnosed with life-threatening physical diseases, such as cancer. ${ }^{36}$ Decreased social support or restricted physical activities during a parent's illness cause children to become anxious. ${ }^{37}$ Previous studies also report that children need people who are close to them in order to feel safe during stressful life events. Anxiety levels are increased, and quality of life is negatively influenced by children who are forced to stay away from their parents in such times. ${ }^{38}$ Furthermore, studies show that it is easier for children to cope if they maintain their daily routines and do not confront changes related to schooling or friends. ${ }^{39,40}$ Measures intended to prevent the spread of COVID-19 involve fundamental changes and restrictions that may pose adaptation-related difficulties for children. All these factors may play a role in the increase in the level of negative thoughts and a decrease in the quality of life of children.

No significant relationship was found between the sociodemographic characteristics and the treatment and quarantine periods of the group of children who were separated from parents diagnosed as COVID-19-positive. To our knowledge, no study has evaluated the influences of isolation periods on the mental health of children. The review of extant literature revealed that children of parents diagnosed with serious illnesses react in different ways depending on age. ${ }^{41}$ Nevertheless, similar to the present study, some previous works reported the absence of a relationship between the anxiety levels experienced by children during parental illness and the children's age or gender. ${ }^{36}$ The very small sample of COVID-19-negative children whose parents were diagnosed with COVID-19 in this study may have also distorted the accuracy of the comparison of anxiety levels in relation to each sociodemographic variable.

This study has a few limitations. The most important one is that face-to-face interviews were not possible due to the risk of infection. Another important limitation is that the individuals' overall hospital records could not be evaluated in terms of treatment variables. Moreover, the small number of parents of COVID-19-positive children who agreed to participate in the study, and the limited number of children diagnosed with COVID-19 may have affected our results. In addition, we did not obtain any information about which parent was COVID-19 positive and who took care of the children after the parents were quarantined. Previous studies were generally conducted with community samples. In addition, number of the studies conducted with children who have been diagnosed with $\mathrm{CO}$ VID-19 and whose parents have also been diagnosed with COVID-19 is very limited. Therefore, the sample of COVID19-positive children and COVID-19-negative children isolated from their parents makes this study valuable. To the best of our knowledge, the present study is the first to compare the anxiety, quality of life, and negative thoughts of COVID-19-positive children and of COVID-19-negative children separated from COVID-19-positive parents.

In conclusion, this study compared the mental health of children exposed to different levels of stress during the COVID-19 outbreak. Findings showed high levels of anxiety and negative thoughts and low quality of life among children whose parents were diagnosed with COVID-19 and were isolated from them. Therefore, the high levels of negative thoughts and low quality of life in this group predicted their high levels of anxiety. Parental quarantine and isolation, especially in children who are vulnerable and with poor quality of life, have negative effects on children's mental health. Clinicians should be aware of this problem and seek help from other mental health professionals to support children's psychological health as needed.

\section{Acknowledgments}

None.

\section{Conflicts of Interest}

The authors have no potential conflicts of interest to disclose.

\section{Author Contributions}

Conceptualization: Şenay Kılınçel, Oğuzhan Kılınçel, Esra Yazıcı, Muhammed Ayaz. Formal analysis: Şenay Kılınçel, Oğuzhan Kılınçel, Erkal Erzincan, Muhammed Ayaz. Methodology: Şenay Kulınçel, Feray Tarımtay Altun, Özgecan Nuryüz, Ezgi Tan, Muhammed Ayaz. Project administration: Şenay Kılınçel, Feray Tarımtay Altun, Özgecan Nuryüz, Ezgi Tan. Supervision: Esra Yazıcı, Muhammed Ayaz. Validation: Şenay Kılınçel, Feray Tarımtay Altun. Visualization: Senay Kılınçel, Feray Tarımtay Altun, Muhammed Ayaz. Writing_original draft: Şenay Kılınçel, Feray Tarımtay Altun, Muhammed Ayaz. Writing-review \& editing: Erkal Erzincan, Esra Yazıc1, Muhammed Ayaz.

\section{ORCID iDs}

Şenay Kılınçel

Feray Tarımtay Altun

Özgecan Nuryüz

Ezgi Tan

Erkal Erzincan

Oğuzhan Kılınçel

Esra Yazıc1

Muhammed Ayaz https://orcid.org/0000-0001-5298-0264 https://orcid.org/0000-0003-3726-8169 https://orcid.org/0000-0002-4753-8823 https://orcid.org/0000-0002-3548-4063 https://orcid.org/0000-0001-6586-4430 https://orcid.org/0000-0003-2988-4631 https://orcid.org/0000-0002-2575-7398 https://orcid.org/0000-0002-9715-3809 


\section{REFERENCES}

1. Fauci AS, Lane HC, Redfield RR. COVID-19-Navigating the uncharted. N Engl J Med 2020;382:1268-1269.

2. Ali SA, Baloch M, Ahmed N, Ali AA, Iqbal A. The outbreak of coronavirus disease 2019 (COVID-19) - an emerging global health threat. J Infect Public Health 2020;13:644-646.

3. Dalton L, Rapa E, Stein A. Protecting the psychological health of children through effective communication about COVID-19. Lancet Child Adolesc Health 2020;4:346-347.

4. Jiao WY, Wang LN, Liu J, Fang SF, Jiao FY, Pettoello-Mantovani M, Somekh E. Behavioral and emotional disorders in children during the COVID-19 epidemic. J Pediatr 2020;221:264-266.e1.

5. Hawryluck L, Gold WL, Robinson S, Pogorski S, Galea S, Styra R. SARS control and psychological effects of quarantine, Toronto, Canada. Emerg Infect Dis 2004;10:1206-1212.

6. Brooks, SK, Webster RK, Smith LE, Woodland L, Wessely S, Greenberg N, Rubin GJ. The psychological impact of quarantine and how to reduce it: rapid review of the evidence. Lancet 2020;395:912-920.

7. Golberstein E, Wen H, Miller BF. Coronavirus disease 2019 (COVID-19) and mental health for children and adolescents. JAMA Pediatr 2020;174:819-820.

8. Masten AS. Competence, Resilience and Development in Adolescence: Clues for Prevention Science: Integrating Brain and Prevention Science. In: Romer D, Walker EF, Editors, Adolescent Psychopathology and the Developing Brain: Integrating Brain and Prevention Science. New York, NY: Oxford University Press, 2007, p.31-52.

9. Grant KE, Compas BE, Thurm AE, McMahon SD, Gipson PY, Campbell AJ et al. Stressors and child and adolescent psychopathology: evidence of moderating and mediating effects. Clin Psychol Rev 2006; 26:257-283.

10. Beck AT. Cognitive Therapy of Depression. New York: Guilford Press; 1979.

11. Laurens KR, Hobbs MJ, Sunderland M, Green MJ, Mould GL. Psychotic-like experiences in a community sample of 8000 children aged 9 to 11 years: an item response theory analysis. Psychol Med 2012;42: 1495-1506.

12. Downs JM, Cullen AE, Barragan M, Laurens KR. Persisting psychoticlike experiences are associated with both externalising and internalising psychopathology in a longitudinal general population child cohort. Schizophr Res 2013;144:99-104.

13. Wong KK, Freeman D, Hughes C. Suspicious young minds: paranoia and mistrust in 8- to 14-year-olds in the U.K. and Hong Kong. Br J Psychiatry 2014;205:221-229.

14. Cole DA, Martin JM, Peeke LG, Seroczynski AD, Hoffman K. Are cognitive errors of underestimation predictive or reflective of depressive symptoms in children: a longitudinal study. Journal of Abnorm Psychol 1998;107:481-496.

15. Golberstein E, Gonzales G, Meara E. How do economic downturns affect the mental health of children? Evidence from the National Health Interview Survey. Health Econ 2019;28:955-970.

16. Salkovskis P, Shafran R, Rachman S, Freeston MH. Multiple pathways to inflated responsibility beliefs in obsessional problems: possible origins and implications for therapy and research. Behav Res Ther 1999; 37:1055-1072.

17. Shevlin M, McBride O, Murphy J, Miller JG, Hartman TK, Levita L, et al. Anxiety, depression, traumatic stress, and COVID-19 related anxiety in the UK general population during the COVID-19 pandemic. BJPsych Open 2020;6: e125.

18. Norredam M, Nellums L, Nielsen RS, Byberg S, Petersen JH. Incidence of psychiatric disorders among accompanied and unaccompanied asylum-seeking children in Denmark: a nation-wide register-based cohort study. Eur Child Adolesc Psychiatry 2018;27:439-446.

19. Birmaher B, Brent DA, Chiappetta L, Bridge J, Monga S, Baugher M. Psychometric properties of the Screen for Child Anxiety Related Emo- tional Disorders (SCARED): a replication study. J Am Acad Child Adolesc Psychiatry 1999;38:1230-1236.

20. Çakmakçı, F. Çocuklarda anksiyete bozukluklarını tarama ölçeği geçerlik ve güvenirlik çalışması. Dissertation. Kocaeli: Kocaeli University; 2004.

21. Leitenberg H, Yost LW, Carroll-Wilson M. Negative cognitive errors in children: questionnaire development, normative data, and comparisons between children with and without self-reported symptoms of depression, low self-esteem, and evaluation anxiety. J Consult Clin Psychol 1986;54:528-536.

22. Karakaya I, Coşkun A, Ağaoğlu B, Öç ÖÇ, Memik NÇ, Çakın Memik $\mathrm{N}$ et al. Çocukluktaki olumsuz düşünceleri değerlendirme ölçeği geçerlik-güvenilirlik çalışması. Türk Psikiyatri Dergisi 2007;18:155-162.

23. Varni, JW, Burwinkle TM, Seid M, Skarr D. The PedsQL ${ }^{\mathrm{TM} *} 4.0$ as a pediatric population health measure: feasibility, reliability, and validity. Ambul Pediatr 2003;3:329-341.

24. Çakın Memik N, Ağaoğlu B, Coşkun A, Uneri OS, Karakaya I.The validity and reliability of the Turkish Pediatric Quality of Life Inventory for children 13-18 years old. Turk Psikiyatri Dergisi 2007;18:353-363.

25. Çakın Memik N, Ağaoğlu B, Coşkun A. Çocuklar İçin Yaşam Kalitesi Ölçeğinin 8-12 Yaş Ergen Formunun Geçerlik ve Güvenirlirliği. Çocuk ve Gençlik Ruh Sağlığı Dergisi 2008;15:87-98.

26. Brooks SK, Webster RK, Smith LE, Woodland L, Wessely S, Greenbert $\mathrm{N}$, et al. The psychological impact of quarantine and how to reduce it: rapid review of the evidence. Lancet 2020;395:912-920.

27. Sprang G, Silman M. Posttraumatic stress disorder in parents and youth after health-related disasters. Disaster Med Public Health Prep 2013;7:105-110.

28. Bosnalı O, Tander B. COVID-19 pandemisi ve çocuk cerrahisi. Çocuk Cerahisi Dergisi 2020;34:1-8.

29. MacEachnie LH, Larsen HB, Egerod I. Children's and young people’s experiences of a parent's critical illness and admission to the intensive care unit: a qualitative meta-synthesis. J Clin Nurs 2018;27:2923-2932.

30. Dyregrov A. Supporting Traumatized Children and Teenagers: A Guide to Providing Understanding and Help. London, United Kingdom: Jessica Kingsley Publishers; 2010.

31. Knutsson S, Samuelsson IP, Hellström AL, Bergbom I. Children's experiences of visiting a seriously ill/injured relative on an adult intensive care unit. J Adv Nurs 2008;61:154-162.

32. Knutsson S, Bergbom I. Children's thoughts and feelings related to visiting critically ill relatives in an adult ICU: a qualitative study. Intensive Crit Care Nurs 2016;32:33-41.

33. Nelms TP, Eggenberger SK. The essence of the family critical illness experience and nurse-family meetings. J Fam Nurs 2010;16:462-486.

34. Rolland JS. Parental illness and disability: a family systems framework. J Fam Ther 1999;21:242-266.

35. Söderström IM, Saveman BI, Hagberg MS, Benzein EG. Family adaptation in relation to a family member's stay in ICU. Intensive Crit Care Nurs 2009;25:250-257.

36. Hauken MA, Senneseth M, Dyregrov A, Dyregrov K. Anxiety and the quality of life of children living with parental cancer. Cancer Nurs 2018;41:E19-E27.

37. Nelson E, Sloper P, Charlton A, While D. Children who have a parent with cancer: a pilot study. J Cancer Educ 1994;9:30-36.

38. Holmes J. John Bowlby and Attachment Theory. 2nd Ed. London: Psychology Press; 1993.

39. Kean S. Children and young people visiting an adult intensive care unit. J Adv Nurs 2010;66:868-877.

40. Kean S. Children and young people's strategies to access information during a family member's critical illness. J Clin Nurs 2010;19:266-274.

41. Heiney SP, Bryant LH, Walker S, Parrish RS, Provenzano FJ, Kelly KE. Impact of parental anxiety on child emotional adjustment when a parent has cancer. Oncol Nurs Forum 1997;24:655-661. 